\title{
Synthesis and Cross-coupling of Sulfonamidomethyltrifluoroborates
}

\author{
Gary A. Molander and Nicolas Fleury-Brégeot \\ Roy and Diana Vagelos Laboratories, Department of Chemistry, University of Pennsylvania, \\ Philadelphia, Pennsylvania 19104-6323, United States
}

Gary A. Molander: gmolandr@sas.upenn.edu

\section{Abstract

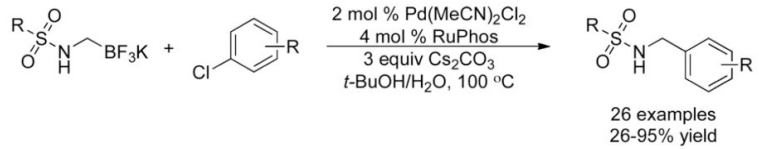

Sulfonamidomethyltrifluoroborates were successfully synthesized and cross-coupled with a wide range of aryl and heteroaryl chlorides, allowing the construction of a sulfonamidomethyl aryl linkage through a new disconnection, thus offering a new way to access such structurally interesting motifs.

Sulfonamides represent a very large and important class of drugs that can be used as antibacterials, diuretics, anticonvulsants, as well as hypoglycemic, anticancer, and antiviral agents. ${ }^{1}$ Among them, arylsulfonamides are the most studied, but arylmethylsulfonamides also constitute an important class of compounds, showing potent activities in several therapeutic areas. ${ }^{2}$ These compounds are commonly synthesized by reacting sulfonyl chlorides and arylmethanamines. ${ }^{3}$ This method, which has proven to be efficient, is nevertheless hampered by the handling and storage of requisite sulfonyl chlorides each and every time a new sulfonamidomethyl target is required. ${ }^{4}$ More recently, reactions starting from sulfonic acids or sulfonate esters have been reported. ${ }^{5}$ Other alternative synthetic methods are reductive aminations of aldehydes with sulfonamides, ${ }^{6}$ reduction of $N$ sulfonylimines, ${ }^{7}$ or the reaction between amines and alcohols. ${ }^{8}$ The latter is usually catalyzed by transition metal complexes via homogeneous catalysis or more recently via heterogeneous catalysis (Scheme 1, routes a and b).

Interestingly, the synthesis of sulfonamidomethyl compounds based on a cross-coupling strategy between an aryl halide and a sulfonamidomethyl coupling partner has not yet been reported. This new disconnection offers an interesting and complementary alternative to existing synthetic routes by allowing the rapid and convenient introduction of a wide range of substituents and also allows enhanced efficiency in the introduction of chemical diversity (Scheme 1, route c).

The Suzuki-Miyaura reaction is one of the most efficient and widely used C-C bondforming reactions. ${ }^{9}$ Our research group has been involved in the synthesis and use of

Correspondence to: Gary A. Molander, gmolandresas . upenn. edu.

Supporting Information Available: Experimental procedures, spectral characterization and copies of ${ }^{1} \mathrm{H},{ }^{13} \mathrm{C},{ }^{19} \mathrm{~F}$ and ${ }^{11_{B}} \mathrm{NMR}$ spectra for all compounds, and X-ray crystallographic data for $\mathbf{2 a}$. This material is available free of charge via the internet at http://pubs.acs.org. 
organotrifluoroborate salts as replacement coupling partners for boronic acids, boronate esters or organoboranes. ${ }^{10}$ Indeed, organotrifluoroborates offer numerous beneficial features such as being air and moisture stable salts that are easy to handle and to store. In addition, the carbon-boron bond remains intact during various chemical transformations on ancillary functional groups. Moreover, they appear to be very efficient coupling partners in SuzukiMiyaura reactions, overcoming many of the drawbacks encountered with other reagents. ${ }^{11}$

In continuation of a project based on the synthesis of functionalized organotrifluoroborates using halomethyltrifluoroborates, alkoxymethyl- and aminomethyltrifluoroborates have been successfully synthesized and used in cross-coupling reactions. ${ }^{12} \mathrm{~A}$ synthetic route based on direct nucleophilic substitution of the halide of potassium halomethyltrifluoroborates proved to be efficient when using mono- or dialkylamines but failed with amides. In 2010, Hiebel and Molander developed an alternative one-pot procedure starting from halomethylboronate esters ${ }^{13}$ and successfully accessed and coupled carboxamidomethyltrifluoroborates with aryl- and heteroaryl chlorides. ${ }^{14}$

In this article we report the synthesis of sulfonamidomethyl derivatives via a SuzukiMiyaura cross-coupling reaction between sulfonamidomethyltrifluoroborates and aryl and heteroaryl chlorides.

Although the halomethyltrifluoroborate strategy also failed for the synthesis of sulfonamidomethyltrifluoroborates, even when preforming the anion of the sulfonamide, the one-pot procedure starting from the chloromethyl boronate ester $\mathbf{1}$ gave access to the desired products 2a-p (Table 1).

Thus, various sulfonyl chlorides, bearing either electron-donating or electron-withdrawing substituents, have been successfully used to afford the trifluoroborates with modest to good yields. The products are all solids that can be stored without particular precautions for several weeks until used in cross-coupling reactions. Compound 2a has been recrystallized, and an X-ray structure has been obtained (Figure 1). The ORTEP drawing shows two potassium cations that actually count for two "half" potassium atoms as they lie on a crystallographic two-fold axis. The cesium mesitylsulfonamidomethyltrifluoroborate $\mathbf{2 b}$ (Table 1, entry 1) analog of the potassium trifluoroborate $\mathbf{2 a}$ has also been prepared by quenching the boronate ester with a solution of cesium hydrogen fluoride $\left(\mathrm{CsHF}_{2}\right)$ as described by Matteson et al. ${ }^{15}$ to determine whether the nature of the cation has any influence during the cross coupling reaction.

Once synthesized, the sulfonamidomethyl- trifluoroborates were tested in Suzuki-Miyaura cross- couplings using aryl chlorides as electrophiles. The conditions were optimized using the mesityl- sulfonamidomethyltrifluoroborate 2a and 4-chloroanisole. Surprisingly, none of the previously reported reaction conditions for aminomethyltrifluoroborates, proved to be effective nor lead to full conversion. This might be explained by the very low solubility of the sulfonamidomethyltrifluoroborates, which require protic solvents (for example, using the best conditions for amidomethyltrifluoroborates, $\mathrm{CPME} / \mathrm{H}_{2} \mathrm{O}$ or $\mathrm{THF} / \mathrm{H}_{2} \mathrm{O}$ mixture led to 9 and $43 \%$ conversion after $24 \mathrm{~h}$, respectively). ${ }^{16}$ Extensive screening of solvent, temperature, Pd source and ligand eventually led to the following conditions: a $1 / 1 t-\mathrm{BuOH} / \mathrm{H}_{2} \mathrm{O}$ solvent mixture, a temperature of $100{ }^{\circ} \mathrm{C}, \mathrm{Pd}(\mathrm{MeCN})_{2} \mathrm{Cl}_{2}(2 \mathrm{~mol} \%)$ as the metal precursor, RuPhos $\left(4 \mathrm{~mol} \%\right.$ ) and $\mathrm{Cs}_{2} \mathrm{CO}_{3}$ (3 equiv), which provided $\mathbf{3 b}$ in $78 \%$ isolated yield (Table 2, entry 2). Further optimization showed that replacing the ligand and the base by XPhos and $\mathrm{NaO} t$ $\mathrm{Bu}$, respectively, increased the yield to $87 \%$. However, those conditions proved to be less general and only improved the yields in a few cases (Table 2).

To investigate the method further, both electron-rich (Table 2, entries 1-6) and electronpoor (Table 2, entries 7-12) aryl chlorides were examined. All of these substrates were 
found to cross couple, providing the sulfonamidomethylated products with yields ranging from 44 to $95 \%$. A large array of functional groups was tolerated, although the yields tended to decrease with delicate substrates such as aldehydes or esters (Table 2, entries 10 and 12).

The effects of steric hindrance were tested with mono- or di-ortho substituted electrophiles (Table 2, entries $3,4,5$ ). The standard conditions proved to be very efficient, as shown by the good yield (78\%) in the reaction of 2-chloro-5-methoxy-1,3-dimethylbenzene, which is a difficult substrate owing to the presence of two ortho substituents. On the other hand, XPhos and $\mathrm{NaO} t-\mathrm{Bu}$ did not provide full conversion and resulted in a $48 \%$ yield even after increasing the catalyst loading (Table 2, entry 4). Hindered and electron-rich 2chloroanisole was used to perform the reaction on a larger scale. On a one gram scale, lowering the catalyst loading to $1 \mathrm{~mol} \%$ of Pd and $2 \mathrm{~mol} \%$ of ligand and using a 1/1 trifluoroborate/electrophile ratio afforded the expected product $3 \mathbf{c}$ with an excellent isolated yield of $91 \%$, emphasizing the robustness of the method (Table 2, entry 3 ). The cesium organotrifluoroborate $\mathbf{2 b}$ was also successfully coupled with 4-chloroanisole in a similar yield, showing that the presence of both potassium and cesium ions did not interfere with the course of the reaction (Table 2, entry 2).

To expand the array of electrophiles, the potassium mesitylsulfonamidomethyl trifluoroborate 2a was coupled with a variety of heteroaromatic chlorides (Table 3). RuPhos and cesium carbonate proved to be the most efficient ligand and base, respectively, as they afforded the highest yields (Table 3, entry 2). An array of these substrates was examined including pyridine, thiophene and furan derivatives. The resulting sulfonamidomethylated heteroaromatics 4a-f were obtained with good to excellent yields from 62 to $92 \%$, while 5chloro-2-furaldehyde coupled with a lower yield.

The scope of this method was further demonstrated by using a variety of arylsulfonamidomethyl potassium trifluoroborates as coupling substrates with 4chloroanisole (Table 4). Both electron rich and electron poor arylsulfonamidomethyl trifluoroborates coupled using the previously defined conditions with yields ranging from 24 to $77 \%$.

We then proceeded to examine the electrophile compatibility using trifluoroborate $\mathbf{2 a}$ (Table 5). The aryl iodide and aryl bromide gave modest yields; various amounts of reduced aryls were observed, suggesting that the transmetallation might be the rate limiting step. The aryl triflate showed the same behavior as chlorides as it coupled with excellent yield (Table 5, entry 4). Phenyl tosylate afforded a good yield $(70 \%)$, while the more difficult mesylate gave a more limited result with a promising yield (53\%) after some modifications of the reaction conditions (Table 5, entry 6).

In conclusion, we have synthesized a variety of potassium arylsulfonamidomethyl trifluoroborates and demonstrated their suitability as coupling partners in Suzuki-Miyaura cross-coupling reactions with both aryl and heteroaryl chlorides. These trifluoroborates can be easily prepared through a one-pot process from 2-(chloromethyl)-4,4,5,5tetramethyl-1,3,2-dioxaborolane, providing a new means for efficiently accessing a large array of structurally diverse and significant sulfonamidomethyl-containing molecules.

\section{Supplementary Material}

Refer to Web version on PubMed Central for supplementary material. 


\section{Acknowledgments}

This research was supported by a National Priorities Research Program (NRP) grant from the Qatar National Research Fund (Grant no. 08-035-1-008) and the NIH (R01 GM-081376). Dr. M. -A. Hiebel (University of Pennsylvania) is thankfully acknowledged for performing preliminary work on the synthesis of sulfonamidomethyltrifluoroborates. Dr. Rakesh Kohli (University of Pennsylvania) is acknowledged for obtaining HRMS data. Dr. Patrick Caroll (University of Pennsylvania) is gratefully acknowledged for performing the X-ray analysis.

\section{References}

1. (a) Drews J. Science. 2000; 287:1960. [PubMed: 10720314] (b) Navia MA. Science. 2000; 288:2132. [PubMed: 10896586] (c) Scozzafava A, Owa T, Mastrolorenzo A, Supuran CT. Curr. Med. Chem. 2003; 10:925. [PubMed: 12678681] (d) Banerjee M, Poddar A, Mitra G, Surolia A, Owa T, Bhattacharyya B. J. Med. Chem. 2005; 48:547. [PubMed: 15658868] (e) Cole DC, Lennox WJ, Lombardi S, Ellingboe JW, Bernotas RC, Tawa GJ, Mazandarani H, Smith DL, Zhang G, Coupet J, Schechter LE. J. Med. Chem. 2005; 48:353. [PubMed: 15658848] (f) Koehler NKU, Yang C-Y, Varady J, Lu Y, Wu X, Liu M, Yin D, Bartels M, Xu B, Roller PP, Long Y, Li P, Kattah M, Cohn ML, Moran K, Tilley E, Richert JR, Wang S. J. Med. Chem. 2004; 47:4989. [PubMed: 15456243] (g) Natarajan A, Guo Y, Harbinski F, Fan Y-H, Chen H, Luus L, Diercks J, Aktas H, Chorev M, Halperin JA. J. Med. Chem. 2004; 47:4979. [PubMed: 15456240]

2. (a) Nirogi RVS, Daulatabad AV, Parandhama G, Mohammad S, Sastri KR, Shinde AK, Dubey PK. Bioorg. Med. Chem. Lett. 2010; 20:4440. [PubMed: 20594839] (b) Holmes CP, Li X, Pan Y, Xu C, Bhandari A, Moody CM, Miguel JA, Ferla SW, Nuria de Francisco M, Frederick BT, Zhou S, Macher N, Jang L, Irvine JD, Grove JR. Bioorg. Med. Chem. Lett. 2005; 15:4336. [PubMed: 16046123] (c) Shen Y, Liu J, Estiu G, Isin B, Ahn Y-Y, Lee D-S, Kapatral V, Wiest O, Oltvai ZN. Proc. Natl. Acad. Sci. USA. 2010; 107:1082. [PubMed: 20080587] (d) Bladh H, Henriksson K, Hulikal V, Lepistö M. WO 2006/046914 A1. (e) Miller T, Witter DJ, Belvedere S. WO 2005/034880 A2. (f) Sun D, Perkins EL, Tugendreich S. WO 03/043578 A2.

3. Paquette, LA., editor. Handbook of Reagents for Organic Synthesis. Chichester, UK: Wiley \& Sons Ltd; 2009. Sulfur-Containing Reagents.

4. (a) Caddick S, Wilden JD, Wadman SJ, Bush HD, Judd DB. Org. Lett. 2002; 4:2549. [PubMed: 12123373] (b) Caddick S, Hamza D, Wadman SJ, Wilden JD. Org. Lett. 2002; 4:1775. [PubMed: 12000296]

5. (a) Caddick S, Wilden JD, Judd DB. J. Am. Chem. Soc. 2004; 126:1024. [PubMed: 14746462] (b) Shaabani A, Soleimani E, Rezayan AH. Tetrahedron Lett. 2007; 48:2185. (c) De Luca L, Giacomelli G. J. Org. Chem. 2008; 73:3967. [PubMed: 18393527]

6. Abdel-Magid AF, Carson KG, Harris BD, Maryanoff CA, Shah RD. J. Org. Chem. 1996; 61:3849. [PubMed: 11667239]

7. (a) Blackwell JM, Sonmor ER, Scoccitti T, Piers WE. Org. Lett. 2000; 2:3921. [PubMed: 11101454] (b) Chase PA, Welch GC, Jurca T, Stephan DW. Angew. Chem. Int. Ed. 2007; 46:8050.

8. (a) Haniti M, Hamid SA, Liana Allen C, Lamb GW, Maxwell AC, Maytum HC, Watson AJA, Williams JMJ. J. Am. Chem. Soc. 2009; 131:1766. [PubMed: 19191700] (b) Da Costa AP, Viciano M, Sanaù M, Merino S, Tejeda J, Peris E, Royo B. Organometallics. 2008; 27:1305. (c) Zhu M, Fujita K, Yamaguchi R. Org. Lett. 2010; 12:1336. [PubMed: 20184342] (d) Shi F, Tse MK, Zhou S, Pohl M-M, Radnik J, Hübner S, Jähnisch K, Brückner A, Beller M. J. Am. Chem. Soc. 2009; 131:1775. [PubMed: 19191701]

9. (a) Miyaura, N. Metal-Catalyzed Cross-Coupling Reactions. De Meijere, A.; Diederich, F., editors. Weinheim: Wiley-WCH; 2004. p. 41-123. (b) Miyaura N. Top.Curr. Chem. 2002; 219:11. (c) Miyaura N, Suzuki A. Chem. Rev. 1995; 95:2457.

10. (a) Molander GA, Canturk B. Angew. Chem. Int. Ed. 2009; 48:9240. (b) Molander GA, Sandrock DL. Curr. Opin. Drug Discovery Dev. 2009; 12:811.

11. (a) For reviews on organotrifluoroborate salts see: (a) Molander GA, Figueroa R. Aldrichim. Acta. 2005; 38:49. (b) Molander GA, Ellis N. Acc. Chem. Res. 2007; 40:275. [PubMed: 17256882] (c) Stefani HA, Cella R, Adriano S. Tetrahedron. 2007; 63:3623. (d) Darses S, Genet J-P. Chem. Rev. 2008; 108:288. [PubMed: 18095714] For mechanistic details on the advantages of trifluoroborates 
over other boron reagents in the Suzuki reaction see: (e) Butters M, Harvey JN, Jover J, Lennox AJJ, Lloyd-Jones GC, Murray PM. Angew. Chem. Int. Ed. 2010; 49:5156.

12. (a) Molander GA, Ham J. Org. Lett. 2006; 8:2031. [PubMed: 16671774] (b) Molander GA, Sandrock DL. Org. Lett. 2007; 9:1597. [PubMed: 17367156] (c) Molander GA, Gormisky PE, Sandrock DL. J. Org. Chem. 2008; 73:2052. [PubMed: 18284257] (d) Molander GA, Canturk B. Org. Lett. 2008; 10:2135. [PubMed: 18439019]

13. For reviews on $\alpha$-haloboronate esters see: (a) Matteson DS. Chem. Rev. 1989; 89:1535. (b) Matteson DS. Tetrahedron. 1989; 45:1859. (c) Matteson DS. Tetrahedron. 1998; 54:10555.

14. Molander GA, Hiebel M-A. Org. Lett. 2010; 12:4876. [PubMed: 20879742]

15. Matteson DS, Malakial D, Pharazyn PS, Kim BJ. Synlett. 2006; 20:3501.

16. See Supporting Information for more details. 


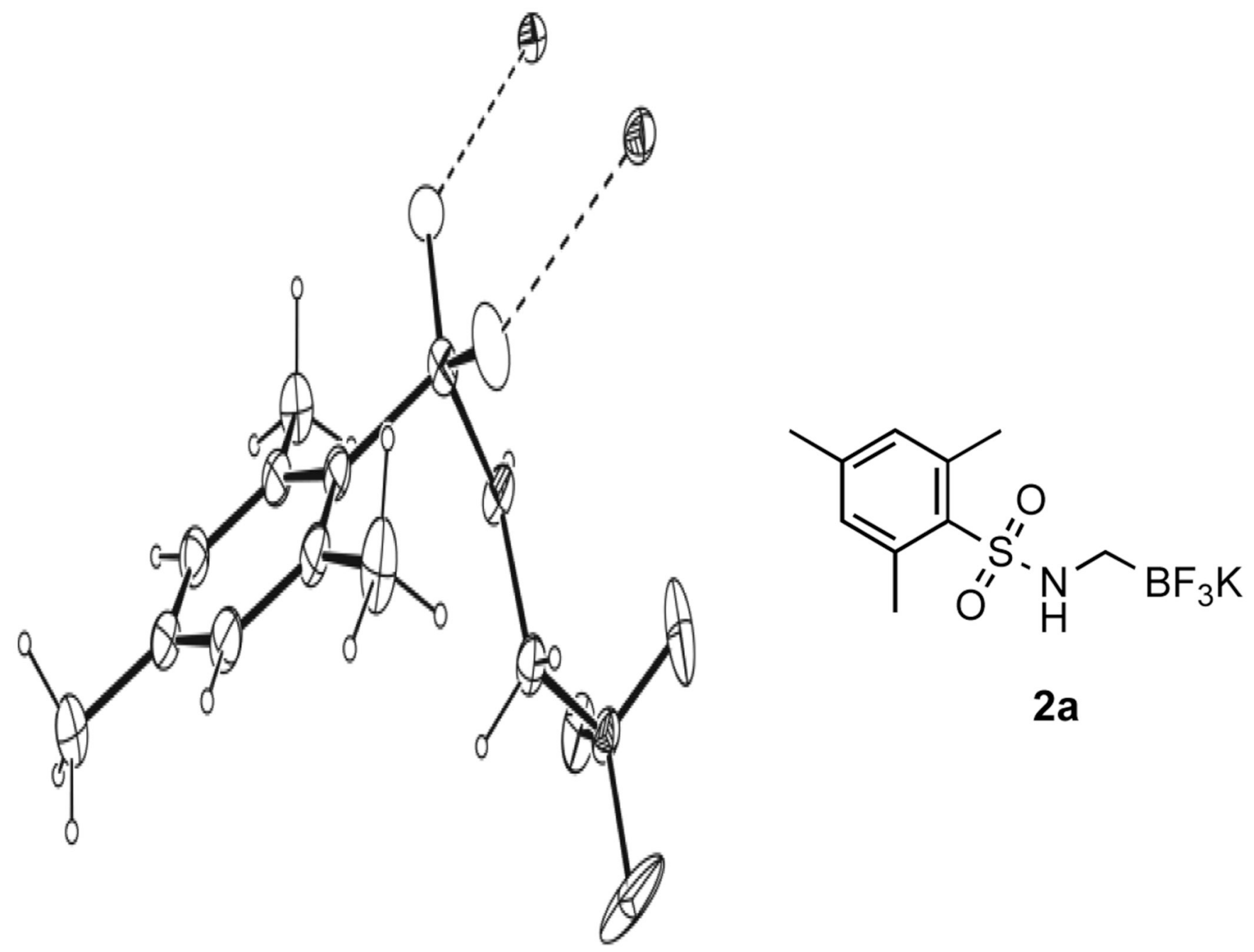

Figure 1.

ORTEP view of sulfonamidomethyl trif luoroborate $\mathbf{2 a}$. 


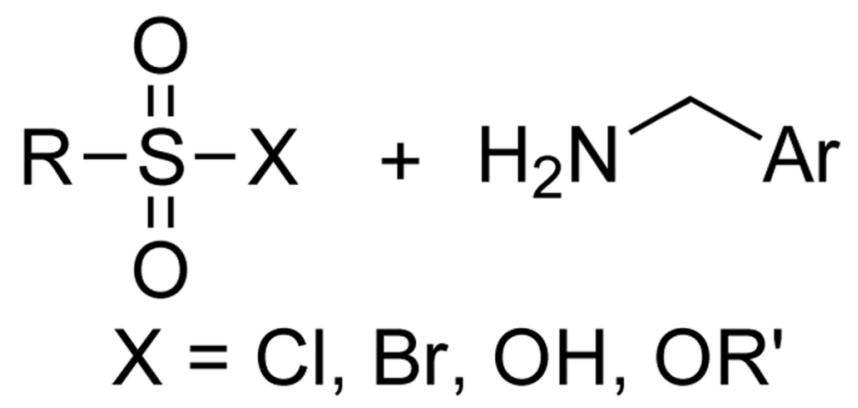<smiles>ClC1CCCCC1</smiles><smiles>CSCC(=O)NS(=O)(=O)P</smiles><smiles>NS(=O)(=O)O</smiles>

0

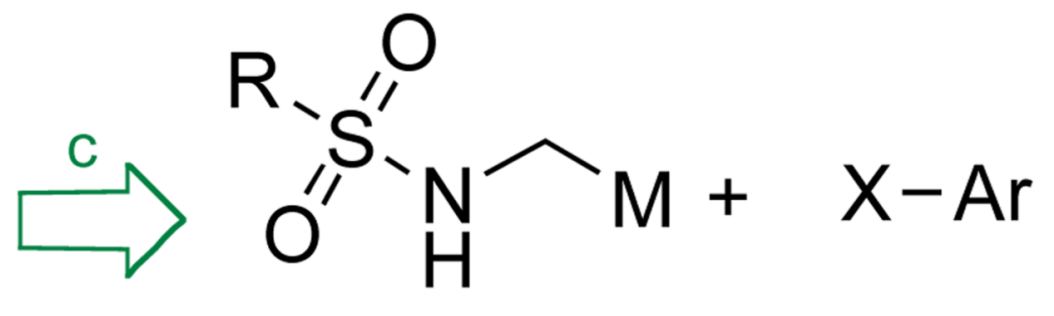

this work

Scheme 1.

Possible disconnections to access the arylsulfonamidomethyl moiety. 


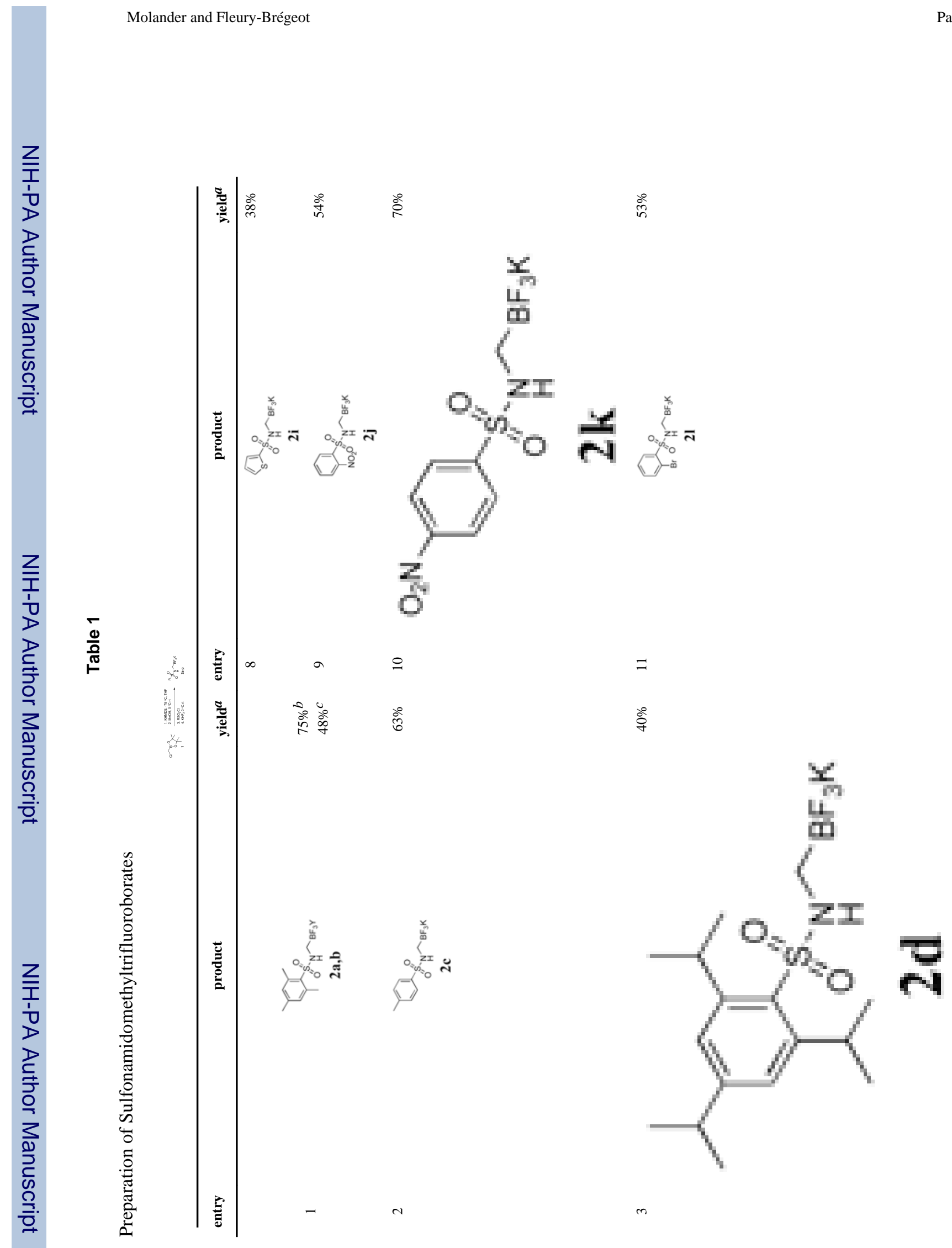

Org Lett. Author manuscript; available in PMC 2012 April 1. 


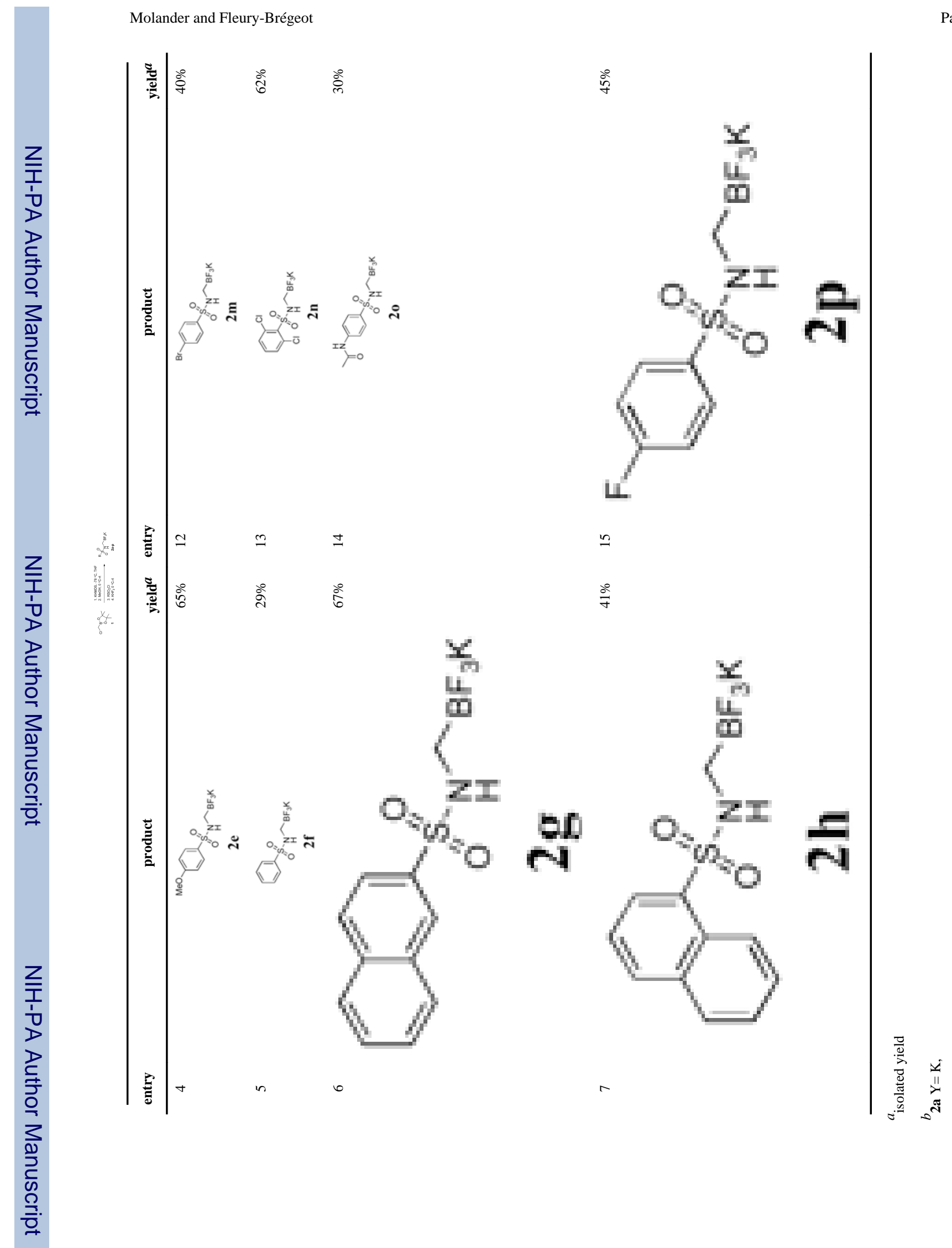

Org Lett. Author manuscript; available in PMC 2012 April 1. 
Table 2

Cross-coupling of 2a with Aryl Chlorides
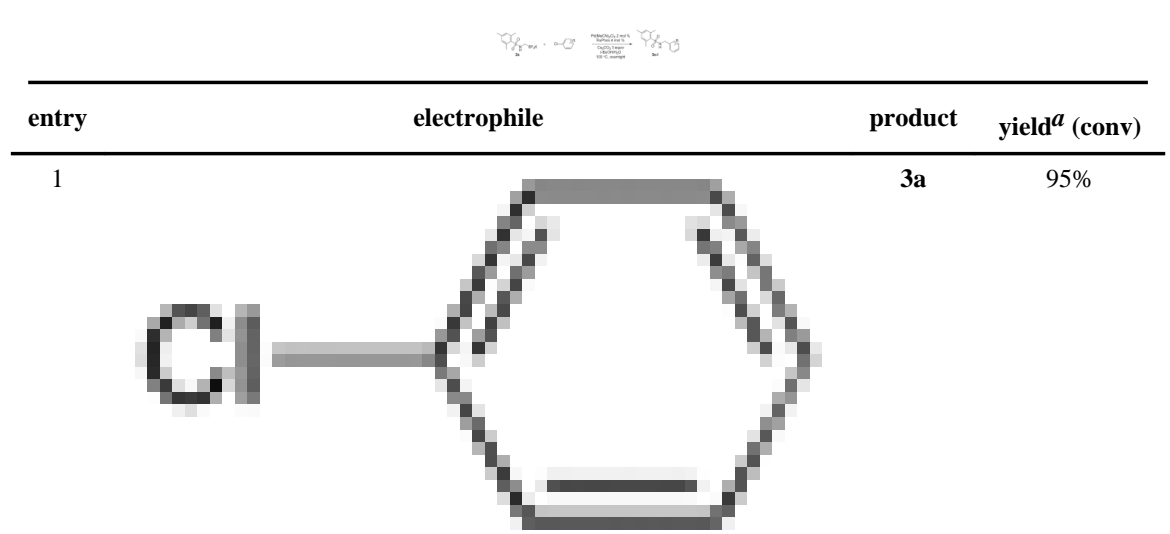
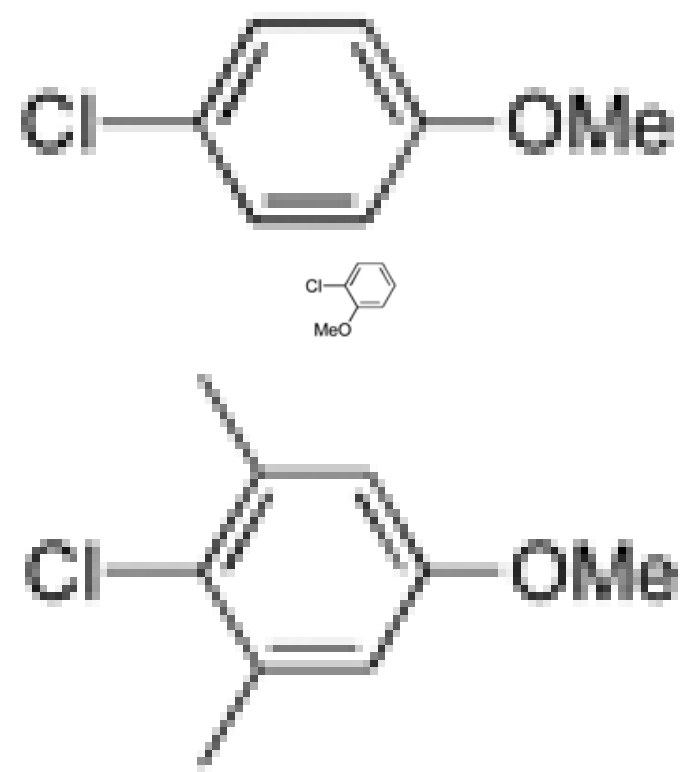

5

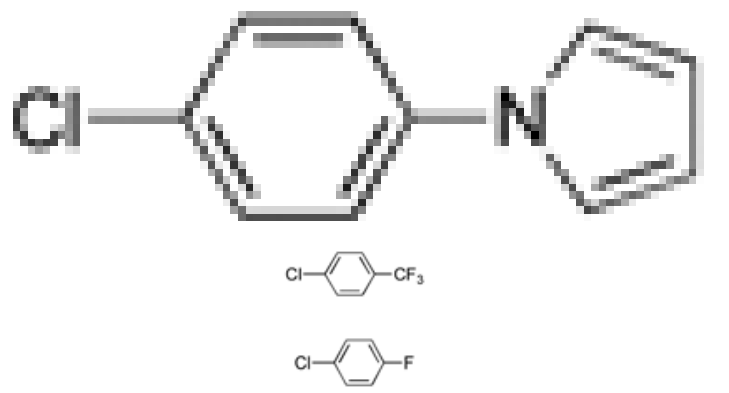

3b $78 \%, 80 \% b$ $87 \% c$

3c $91 \%, 91 \% d$

3d

$78 \%$ $48 \%(57 \%)^{c}, e$

3e

$91 \%$

3f

$91 \%$

$3 g \quad 61 \%$

3h $\quad 87 \%$

Org Lett. Author manuscript; available in PMC 2012 April 1. 


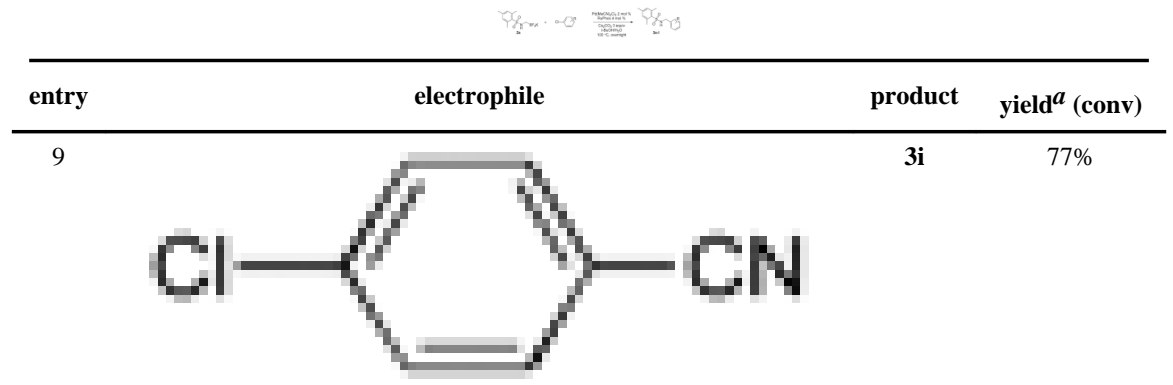

10

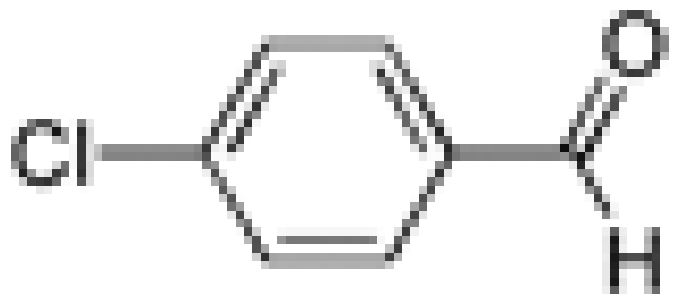

3j

$51 \%$

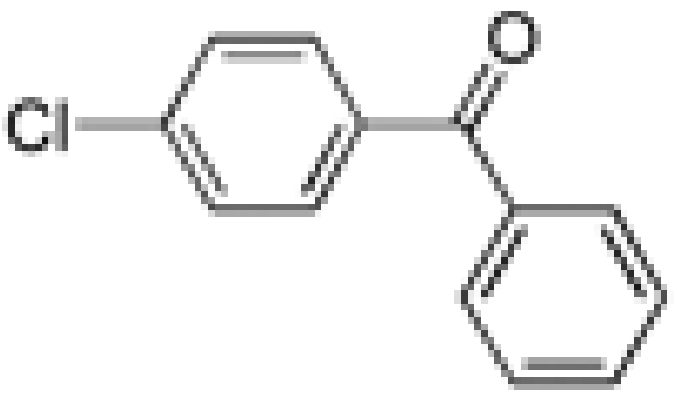

3k

$55 \%$

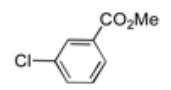

31

$44 \%$

Reaction conditions: 1.0 equiv of aryl chloride, 1.2 equiv of trifluoroborate, 3 equiv of $\mathrm{Cs}_{2} \mathrm{CO}_{3}, \mathrm{~L} / \mathrm{Pd}=2, t-\mathrm{BuOH} / \mathrm{H}_{2} \mathrm{O}: 1 / 1,100{ }^{\circ} \mathrm{C}$, overnight (14-18 h).

$a_{\text {Isolated yield. }}$

${ }^{b}$ Reaction performed with the cesium trifluoroborate $\mathbf{2 b}$.

${ }^{c}$ XPhos (4 mol \%) and $\mathrm{NaO} t$-Bu (3 equiv) instead of RuPhos and $\mathrm{Cs}_{2} \mathrm{CO}_{3}$.

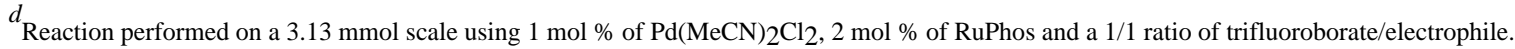

$e_{4 \mathrm{~mol} \%} \%$ of Pd(II) and $8 \mathrm{~mol} \%$ of ligand used. 
Table 3

Cross-coupling Reaction of 2a with Heteroaryl Chlorides

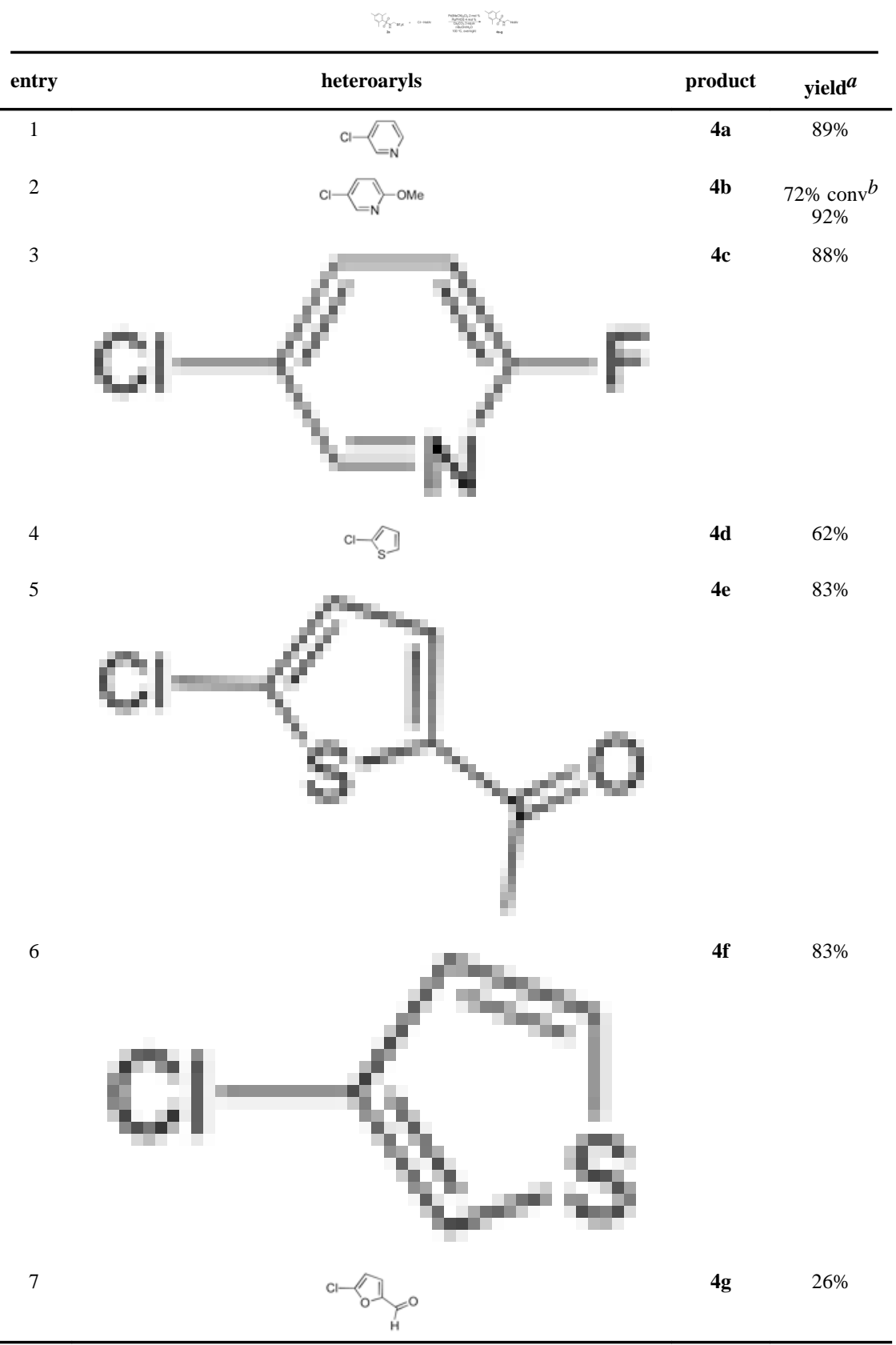

Reaction conditions: 1.0 equiv of aryl chloride, 1.2 equiv of trifluoroborate, 3 equiv of $\mathrm{Cs}_{2} \mathrm{CO}_{3}, \mathrm{RuPhos} / \mathrm{Pd}=2, t-\mathrm{BuOH} / \mathrm{H}_{2} \mathrm{O}: 1 / 1,100{ }^{\circ} \mathrm{C}$, overnight (14-18 h).

${ }^{a}$ Isolated yield.

${ }^{b}$ Obtained using XPhos (4 mol \%) and $\mathrm{NaO} t$-Bu (3 equiv). 
Table 4

Variation of the Trifluoroborate Moiety

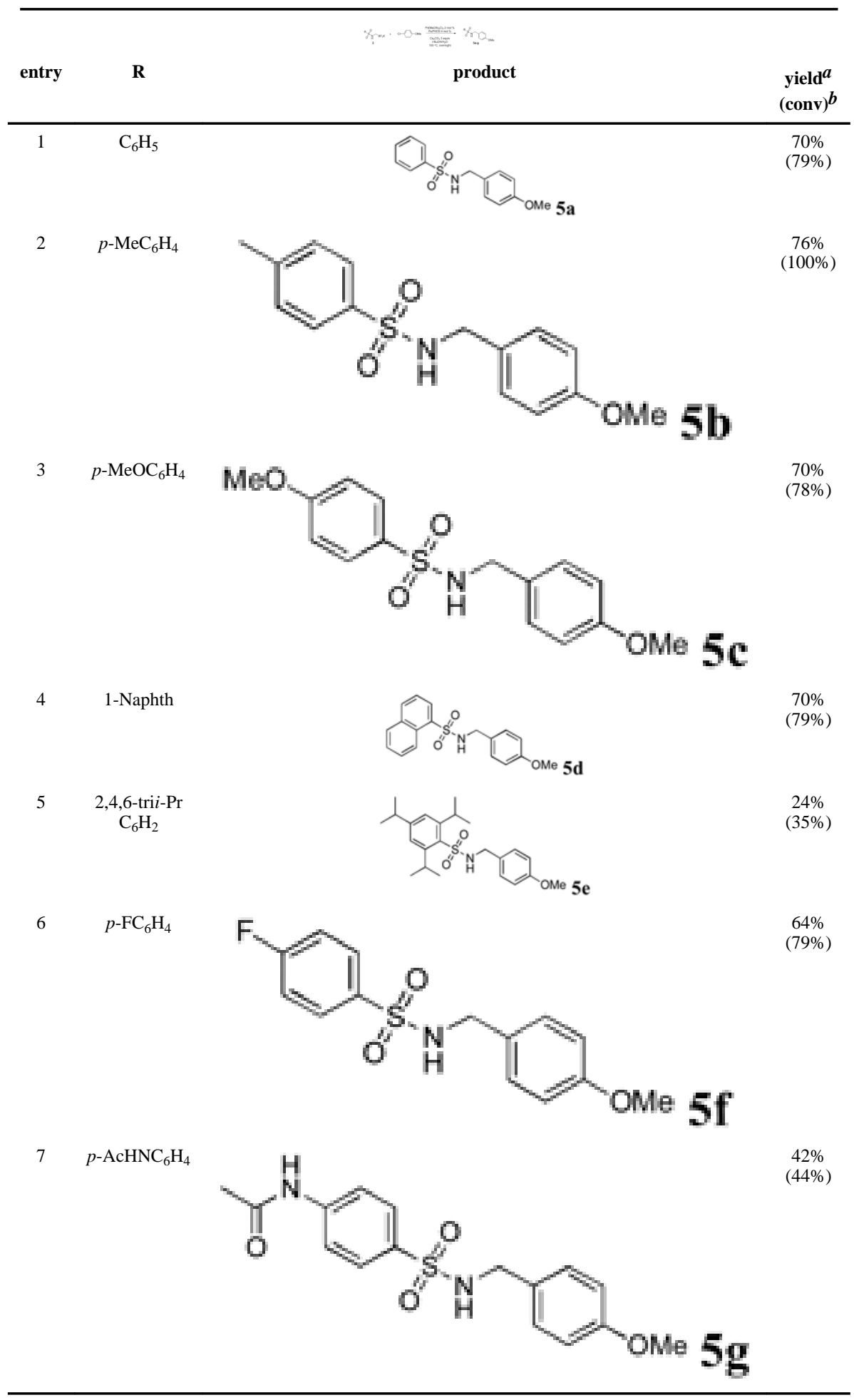

Org Lett. Author manuscript; available in PMC 2012 April 1. 
$a_{\text {isolated yield. }}$

$b_{\text {conversion measured by }}{ }^{1}$ H NMR. 
Table 5

Electrophile Compatibility

\begin{tabular}{ccc}
\hline & & \\
\hline entry & $\mathbf{X}$ & yield $^{a}$ \\
\hline 1 & $\mathrm{Cl}$ & $95 \%$ \\
2 & $\mathrm{Br}$ & $61 \%$ \\
3 & $\mathrm{I}$ & $55 \%$ \\
4 & OTf & $95 \%$ \\
5 & OTs & $70 \%$ \\
6 & OMs & $33 \%(46 \%)^{b}$ \\
& & $53 \% c^{c}$ \\
\hline
\end{tabular}

Reaction conditions: 1.0 equiv of aryl chloride, 1.2 equiv of trifluoroborate, 3 equiv of base, $\mathrm{L} / \mathrm{Pd}=2, t-\mathrm{BuOH} / \mathrm{H}_{2} \mathrm{O}: 1 / 1,100{ }^{\circ} \mathrm{C}$, overnight $(14-18$ h).

${ }^{a}$ Isolated yield.

${ }^{b}$ Catalyst loading $5 \mathrm{~mol} \%$, ligand $10 \mathrm{~mol} \%$.

${ }^{c} \mathrm{~K}_{3} \mathrm{PO}_{4}$ used instead of $\mathrm{Cs}_{2} \mathrm{CO}_{3}$. 